\title{
Capacity waste management at automotive industry in India: A Six Sigma observation
}

\author{
Rajeev Rathi ${ }^{a^{*}}$, Dinesh Khanduja ${ }^{b}$ and S.K.Sharma ${ }^{c}$
}

${ }^{a}$ Research Scholar, Department of Mechanical Engineering, National Institute of Technology, Kurukshetra, Haryana, India, 136119

${ }^{b}$ Professor, Department of Mechanical Engineering, National Institute of Technology, Kurukshetra, Harvana, India, 136119

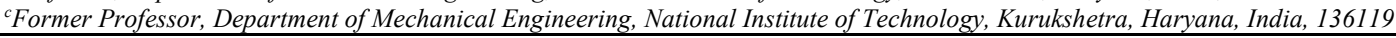

CH R O N I C L E

Article history:

Received October 5, 2015

Received in revised format

December 162015

Accepted February 182016

Available online

February 192016

Keywords:

DMAIC Approach

Automotive industries

Capacity waste

Six Sigma

D-Phase

Process capability

\section{A B S T R A C T}

The companies in present challenging world are trying hard to improve their productivity and capacity utilization levels without actually increasing the sale price of their products. In India, in today combative world, the majority of automotive manufacturing industries are scuffling hard with their low levels of productivity. Possibly there are different reasons for this and capacity waste or under-utilization of productive capacity in industries appears to be one of the prime reasons. As corrective action, the present study makes an effort to check the efficacy of Six Sigma approach to improve capacity waste management. With a case study, through successful execution of Define phase, the study confirms the perception of Six Sigma for capacity waste management in Indian automotive industry.

(C) 2016 Growing Science Ltd. All rights reserved.

\section{Introduction}

Automotive industry is the key driver of any rising nation. It plays a key role in country's fast economic and industrial development (Hadjleld et al., 2015). It facilitates the improvement in various infrastructural services like, transport and power. Owing its deep forward and backward linkages with almost every segment of the country, the automobile industry has a tough and constructive effect and thus propels progress of a nation (D'costa, 1995). The automotive industry comprises of the automobile and the auto component division. It includes passenger cars, multi utility vehicles, commercial vehicles, scooters, motor-cycles, three wheelers, tractors, etc. besides auto components like engine parts, transmission parts, braking and suspension parts, electrical parts, chassis and body parts etc. (Ghosh et al., 2010). In India, this sector is one of the largest industries showing impressive growth over the years and has been significantly making increasing contribution to overall industrial development in the country. The automotive industry is one of India's major sectors; accounting for $22 \%$ of manufacturing growth domestic product (GDP) of the country. The automobile industry of India, comprising two wheelers, three wheelers, commercial vehicles and passenger cars, the world's second biggest

* Corresponding author. Tel.: +91-1744-233455, Mob.: +91-9996886672 Fax: +91-1744-233455

E-mail address: rajeevrathi_1443@nitkkr.ac.in (R. Rathi) 
manufacturer of two wheelers and the sixth-largest of four wheelers as well as largest manufacturer of tractors in the world, with an installed capacity of 24.76 million vehicles in 2011-12 (SIAM, 2013). The sector has shown great advances in terms of growth, multiply, absorption of latest technology and flexibility in the wake of changing business scenario. Despite heavy demand in the market, automotive industry in India is feeling seriously concerned on poor capacity utilization levels. Table 1 shows a comparison of average capacity utilization levels of manufacturing sector in some countries with that in India. This trend is almost similar in the automotive sector.

\section{Table 1}

Average Utilization rates worldwide

\begin{tabular}{lcl}
\hline Major Countries & Average capacity utilization (\%) & \multicolumn{1}{c}{ Source } \\
\hline USA & 79 & Federal reserve measure \\
Japan & $83-86$ & Bank of Japan \\
European union & 82 & Bank of Spain \\
Australia & 81 & National bank estimates \\
India & 69 & FICCI Estimates \\
Canada & 82 & Statistical Canada \\
Turkey & 79 & Turkey statistical institute \\
\hline
\end{tabular}

Basically, capacity can be defined as the actual or potential capability to perform. It is the whole productive capability of all the utilized productive resources including personnel, machines and technology (Alp \& Tan, 2008). Improved capacity waste management and its assessment derive its importance from the fact that if properly reviewed, it may provide a reliable indication of early growth in an economy (Corrado \& Mattey, 1997). Capacity management is the overall resource utilization effectiveness of the business (Ray, 2013).Capacity waste can be defined as the percentage of total capacity that is actually being unutilized in a specified time. It measures the rate with which productive capacity of the industry is being used at a given scale (Mukherjee \& Misra, 2012). When capacity management is proper then the lessening in the probability of technological retreat becomes noticeable (Krüger, 2008).Capacity estimates are desirable because under-utilization is often cited as a major reason for lower productivity of manufacturing industries around the world. Capacity waste management has been an important sign of fiscal presentation, since it is directly related to output, services and personnel strength of a firm (Gajanan \& Malhotra, 2007). Capacity management plays a key role in improving productivity, inventory, turnover and industrial development. Better capacity management can enhance average annual returns by 3-4\% (Orr, 1999). Literature shows that capacity waste is an essential strategic problem and various researchers have used several techniques like data envelopment analysis(DEA) (Kumar \& Arora, 2010), operations research techniques (Felthoven, Horrace, \& Schnier, 2009), mathematical modeling (Marsudi et al., 2009), regression analysis (Zhang et al., 2008) and many more but their application in effective capacity utilization has been limited and ineffective. In this context Six Sigma is emerging as a well-organized improvement strategy that focuses on developing and delivering stable product and services in a consistent way. It is a systematic strategy for attaining operational supremacy and continuous process improvement (Antony, Kumar, \& Tiwari, 2005).Six Sigma is a business improvement methodology developed to drastically reduce organizational under-utilization thus ultimately increasing profits. It is based on elimination of defects by stressing on perceptive measuring and improving processes (Esposto \& Belt, 2009). It has turn out to be the synonym for enhancing productivity, quality, reducing cost and increasing customer loyalty (Bertels, 2003). It is an organizational approach that utilizes simple statistical tools to achieve profitability and improvement in process and quality through focusing on reduction and eliminating defects in any business process (Hahn et al., 1999). It is a statistical based process improvement methodology that aims to improve process/reduce defects by identifying and eliminating causes of variation in business processes. Sigma is the Greek letter used to represent standard deviation in statistics. Six Sigma stands for six standard deviations from mean (Bertels, 2003; Hoerl \& Snee, 2010). An important clarification about Six Sigma is that, it measures defect opportunities and not defectives. The extra complicated a product or process, the more opportunities of defect it has 
(Henderson \& Evans, 2000). It aims for processes to be enhanced, so that problems don't arise, in its place of just finding short term solutions to the problems. The successful Six Sigma allows saving the cost of poor quality and capacity waste which amounts to $20-40 \%$ of total revenue (Pyzdek \& Keller, 2003). The importance of Six Sigma in many Indian industries has been growing as a powerful business improvement methodology. It has been observed that the use of Six Sigma within Indian industries is limited to few pilot studies only (Antony \& Desai, 2009). All Six Sigma projects are executed through well-known DMAIC methodology i.e. Define, Measure, Analyze, Improve, and Control. Each step is designed to help an organization to make improvements in business processes (Cheshmberah \& Nabavi, 2014; Li et al., 2008). It cites to a data-driven improvement cycle used for optimizing, improving and stabilizing company processes and plans. The DMAIC improvement methodology is the major tool used to drive Six Sigma projects (Goh, 2002; Sonphuak \& Rojanarowan, 2013). In Define phase, those key processes are recognized that need improvement and then these are studied and analyzed in the Measure and Analyze phases. Then in Improve phase, a process is changed for better to get optimum results followed by Control phase which ensures sustained results beyond the completion (Dahlgaard \& Dahlgaard-Park, 2006). A large number of research papers are available on Six Sigma; the topic is still growing and offers great opportunities for further research and development. Its applications and execution cases in large manufacturing organizations are limited, so there is wide scope to explore Six Sigma applications for automotive industries. Six Sigma as a business improvement strategy has been implemented to achieve benefits like to improve quality, reduce scrap, process improvement, reduce cost, reduce cycle time etc. (Linderman et al., 2006; Zu et al., 2008), but there is no evidence to show that Six Sigma is used for broadly reducing capacity waste levels. Literature lacks any evidence on exploration of Six Sigma to reduce capacity waste levels. Literature shows that Indian automotive industries are still not familiar with the efficacy and sustainable benefits of Six Sigma. The main objective of present study is to confirm; can Six Sigma be effectively implemented in automotive industries to improve industrial productive capacity, so as to ultimately improve the productivity?

\section{Case study}

A case study was carried out at a premier automotive industry in India. The division is the original equipment manufacturer (OEM) of shock absorbers and is the market leader in this field with an installed capacity of 3.2 million shock absorbers/struts and 0.3 million fork fronts per annum.

\section{Table 2}

Capacity waste data

\begin{tabular}{ccccc}
\hline Months & Installed capacity & Actual capacity & Capacity Utilization (\%) & Capacity Waste (\%) \\
\hline Oct -12 & 250000 & 157655 & 63.06 & 36.94 \\
Nov & 250000 & 161385 & 64.55 & 35.45 \\
Dec & 250000 & 168723 & 67.49 & 32.51 \\
Jan-13 & 250000 & 184199 & 73.68 & 26.32 \\
Feb & 250000 & 164725 & 65.89 & 34.11 \\
March & 250000 & 191086 & 76.43 & 23.57 \\
April & 250000 & 137182 & 54.87 & 45.13 \\
May & 250000 & 157074 & 62.83 & 37.17 \\
June & 250000 & 169876 & 67.95 & 32.05 \\
July & 250000 & 171563 & 68.63 & 31.37 \\
August & 250000 & 175746 & 70.30 & 29.70 \\
Sept & 250000 & 168051 & 67.22 & 32.78 \\
Oct & 250000 & 142453 & 56.98 & 43.02 \\
Nov & 250000 & 173987 & 69.59 & 30.41 \\
Dec & 250000 & 163475 & 65.39 & 34.61 \\
\hline Jan-14 & 250000 & 209012 & 83.60 & 16.40 \\
\hline Feb & 250000 & 151436 & 60.57 & 39.43 \\
March & 250000 & 154657 & 61.86 & 38.14 \\
\hline
\end{tabular}


For initializing Six Sigma project, capacity waste data of 18 months (October 2012 to March 2014) was collected (See Table 2) to define the problem in an appropriate manner. Defining the problem in any Six Sigma project is very critical issue because $40 \%$ of projects get failed due to improper project definition. Main focus of define phase is on the customers and their priorities. The main aim of this phase is to find out critical to quality characteristics (CTQs), that which one have the most impact on quality or process (Henderson \& Evans, 2000). SIPOC diagram, Trend analysis, Pareto analysis, Project charter and Process capability analysis have been used as defining tools in define phase to carry out Six Sigma project.

For initialization of the process Trend Analysis was performed. It is the practice of collecting information and attempting to mark a pattern, in the information. In statistics, trend analysis frequently refers to method for extracting an underlying pattern of behavior in a time series which would otherwise be partly or nearly completely hidden. An easy explanation of these methods is trend evaluation, which can be taken on inside a formal analysis. In starting of project main effect of capacity waste trend analysis has been plotted as shown in Fig. 1. The trend plot shows the original data, the fitted trend line and analyzed that the mean capacity waste per month is $33.28 \%$ which causing considerable time and capital losses. The output also shows three measures of accuracy that help to determine the accuracy of the fitted values. Three measures are:

MAPE (mean absolute percentage error) $=17.5379$

MAD (mean absolute deviation) $\quad=4.9390$

MSD (mean standard deviation) $\quad=43.7207$

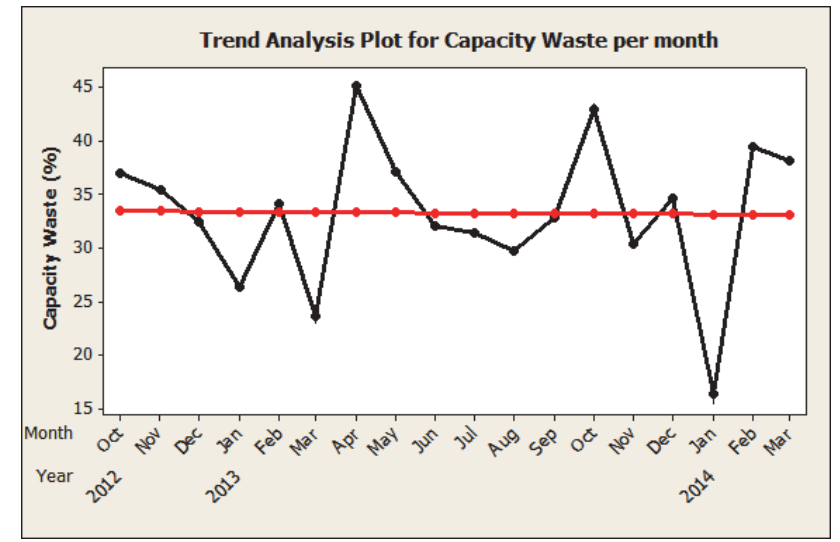

Fig. 1. Trend analysis plot for capacity waste

In next Pareto analysis was carried out. It is a Quality Assurance tool that positions the data categorization in the downward order from the highest possibility of happening to the lowest possibility of happening. The total possibility is associated to 100 per cent. Pareto Analysis uses the Pareto Principle also known as the " $80 / 20$ Rule" which is the idea that 20 percent of causes generate 80 percent of results (Karuppusami \& Gandhinathan, 2006). This huge capacity waste is a very poor Fig. which causing serious attention towards it. Major reasons for this capacity waste are identified and are shown with the help of pie chart in Fig. 2. As evident from Fig. 2, major reasons for capacity waste are machine down time (68\%), defective parts (13\%) and reworks (9\%). To find out $\mathrm{m} / \mathrm{c}$ down time of various shops, 18 months of $\mathrm{m} / \mathrm{c}$ down time data is collected in various shops and Pareto chart was drown for finding maximum downtime occurs in which shop (see Fig. 3). Pareto analysis facilitate to recognize the "vital few' from 'trivial many' and provide direction for selecting projects for improvements (Juran, 1954). The single line joining the histogram shows the cumulative frequency of shops at each stage. In the present case Pareto chart shows shox machine shop and metal finishing shop comprising maximum down time and these are the prime sources for capacity waste. 


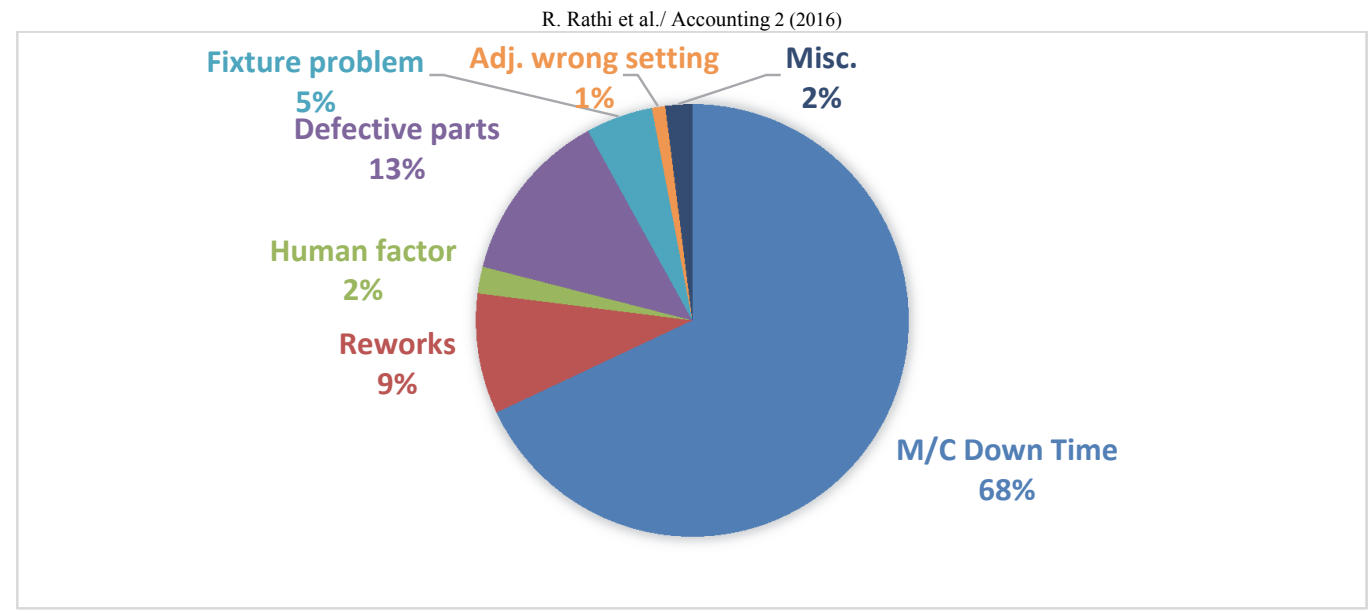

Fig. 2. Major Reasons for Capacity Waste

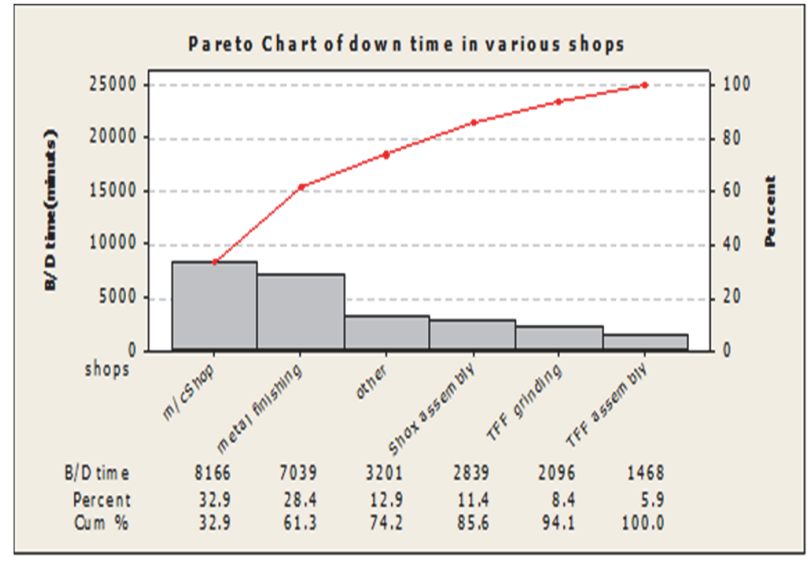

Fig. 3. Pareto chart for shop wise down time

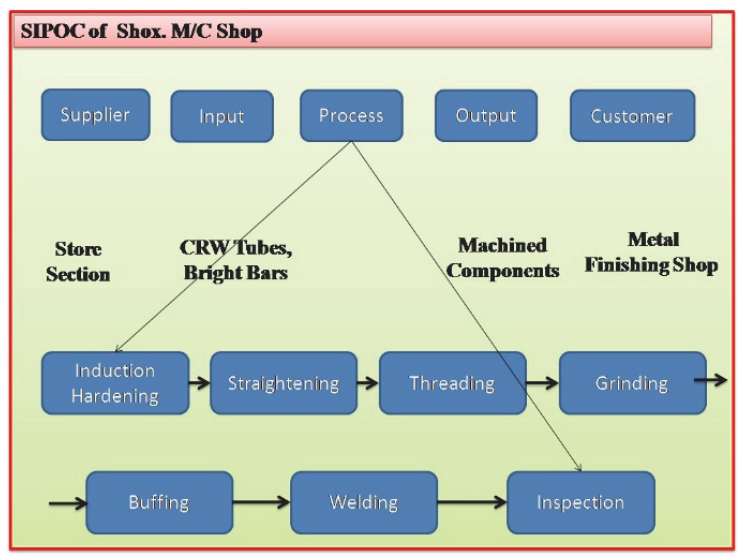

Fig. 4. SIPOC Diagram of M/C Shop

Further next SIPOC diagram was constructed. SIPOC (supplier, input, process, output, and customer) is a diagram for filing a process from starting to finish. It is a define tool used by Six Sigma team to recognize all applicable basics of a process improvement project ahead of job initiates. It assist to define a intricate project that may not be well in reach, and is usually in a job at the define phase of the Six Sigma DMAIC methodology (Simon, 2007). Key purpose of SIPOC is to make sure that the team members understand the boundaries with a clear start of the process and end of the process that meets the scope defined in the contract. Fig. 4 demonstrates the SIPOC diagram of machine shop.

After problem was defined comprehensively, then it was converted into a feasible project and this can explained by project charter as described in Fig. 5. The project charter is the first step and one of the most important parts of any Six Sigma assignment. The charter furnishes an outline of the project and serves as an agreement between management and the Six Sigma team regarding the expected project outcome. The charter is used to set the project direction and define the measures of achievements. It comprises an apparent definition of liability and team roles and responsibilities. The charter offers the project team a roadmap of the project boundaries and aligns the goals with critical business needs (Hayes, 2000). It contains crystalline picture of project, its aims, project details, resources available and project team etc. Once the charter has been converted the given problem into a project, next plan is to carry out future map by brainstorming sessions among all team members for systematic execution of the project. The whole project will be a combination of further Six Sigma phases namely measure, analyze, improve and control. By analyzing Pareto Chart closely it is seen that shops causing maximum $\mathrm{m} / \mathrm{c}$ down time are shox $\mathrm{m} / \mathrm{c}$ shop $(32.9 \%)$ and metal finishing $(28.4 \%)$. As indicated in project charter, $\mathrm{m} / \mathrm{c}$ shop down time is main issue for further improvement for the success of project. At this stage process capability of whole process is analyzed in terms of capacity waste (See Fig. 6). 


\begin{tabular}{|c|c|c|}
\hline \multicolumn{3}{|c|}{ Project Charter } \\
\hline $\begin{array}{c}\text { Project Title: } \\
\text { Waste }\end{array}$ & $\begin{array}{c}\text { Reduction in Capacity } \\
\text { Project Location : } \\
\text { Faridabad, India }\end{array}$ \\
\hline Project KPOV(s): & \multicolumn{2}{|c|}{ Duration of M/C shop downtime } \\
\hline Goal Statement: & $\begin{array}{c}\text { To reduce downtime in centre less grinding } \\
\text { lines from 89 hrs to 30 hrs/month }\end{array}$ \\
\hline \multicolumn{2}{|c|}{ Project related Dates: } & Resources: \\
\hline Phases & Start Dates & Role \\
\hline Define & $01-10-13$ & Research Scholar \\
\hline Measure & $20-12-13$ & Production Engineer \\
\hline Analyze & $25-03-14$ & Maintenance Supervisor \\
\hline Improve & $16-05-14$ & QC supervisor \\
\hline Control & $20-06-14$ & Technician \\
\hline
\end{tabular}

Fig. 5. Six Sigma Project Charter

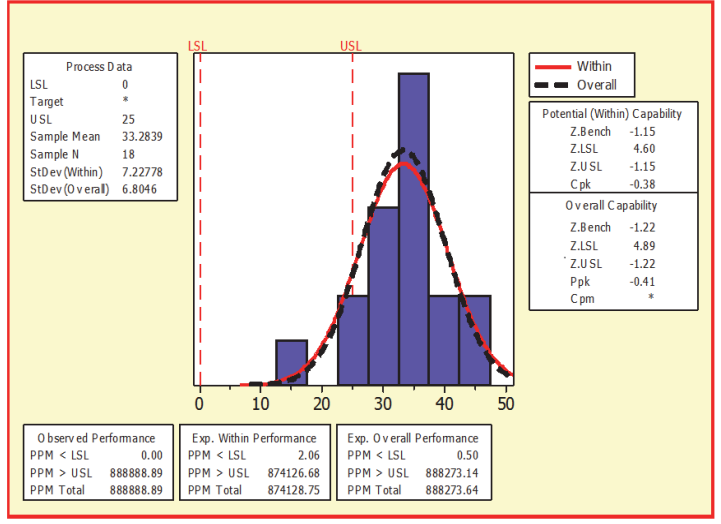

Fig. 6. Process Capability

Process capability compares the output of an in-control process to the specification limits by using capability indices. The comparison is made by forming the ratio of the spread between the process specifications to the spread of the process standards. In Six Sigma line of attack, process performance is reported to the organization as a level of sigma. The better the sigma level, healthier the process or quality. Fig. 6 show that cpk of the process is -0.38 and the corresponding sigma level to cpk is -1.15 which is quite low having overall standard deviation 6.8046 which show a quite unstable process. Parts per million above upper specification limit are 888888.89 in observed performance, which shows that a large number of none confirming parts of the process lie outside the specification limit.

\section{Down time analysis of shop machine}

In Shox machine shop failure data of involved machines has been collected for last 18 months. The operating time of these machines was $9900 \mathrm{hrs}$. Failure data with respect to each machine was analyzed and respective MTTR (Mean time to repair) and MTBF (Mean time between failure) was calculated. From the obtained results MTBF observed to be very low. The graphical interpretation was drawn from collected data using Minitab 16 in form of growth curves. Growth curves are graphical representation of how the failure time increases over time. These curves are used in statistics to determine the type of growth pattern of the failure time. Growth curves are drawn to analyze data from a repairable system. Mean number of failure and rate of occurrence of failure with time has been analyzed through these curves. Minitab suggested two types of models for estimating parametric growth curves, first is powerlaw process that is used to model failure time that can be increasing, decreasing and constant. Second one is homogeneous Poisson process that is used to model failure rate that remains stable over time. If the MCF plot is either concave up or concave down, a power-law process is appropriate. The estimate of the shape (1.7752) is greater than 1, indicating that the failure rate is increasing over time. The event plot (refer Fig. 7) seems to show a pattern of failures that become more frequent as time goes on.

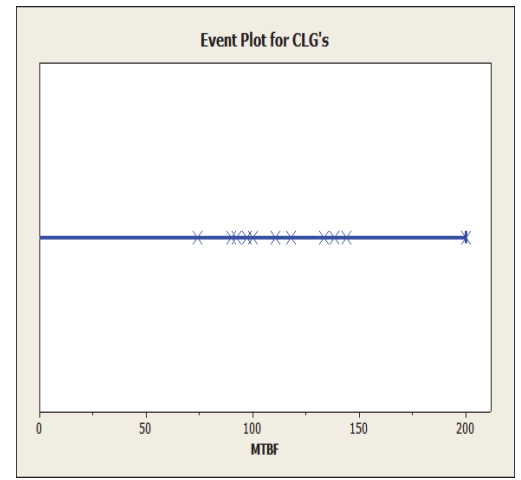

Fig. 7. Event plot

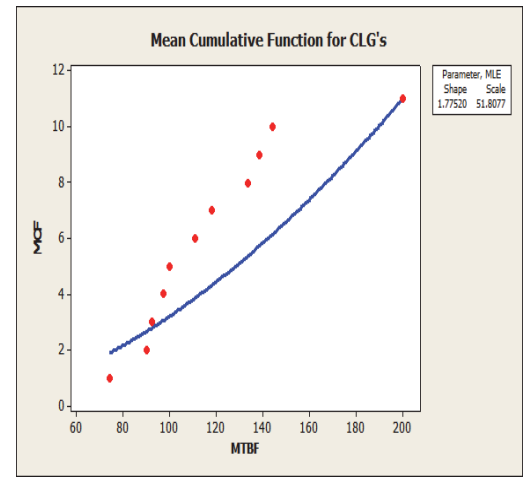

Fig. 8. MCF plot

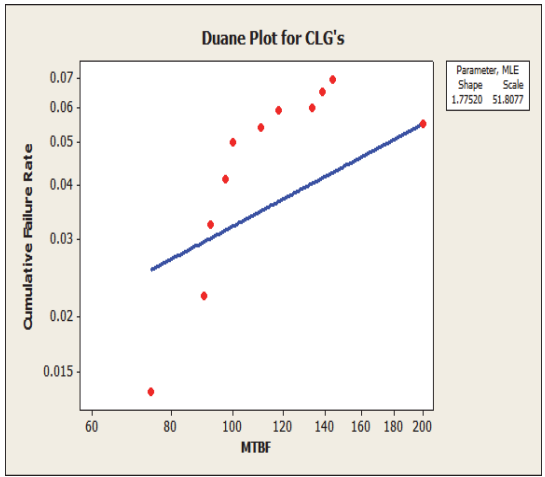

Fig. 9. Duane plot 
The plot of the MCF versus time (refer Fig. 8) shows a curve that is concave up. This plot is consistent with a shape that is greater than one, or a system that is deteriorating. In the Duane plot, a negative slope shows reliability improvement, positive slope shows reliability deterioration and horizontal line shows a constant reliability. In present case, Duane plot (See Fig. 9) shows a positive slope, which means that the system is deteriorating with time. So after analysing the down time data, using Minitab 16 , it is concluded that there is a serious problem of capacity waste inside the selected site.

\section{Conclusion}

In this study, a tactical approach has been used to define capacity waste levels in automotive industry using Six Sigma methodology. With successful implementation of the Define phase, current study breaks certain myths on effectiveness of Six Sigma for performance improvement at automotive industries. It is relatively strange to see successful application of Six Sigma in Indian automotive industries. In present study Machine downtime is emerging as the major critical to quality (CTQ) issue during assessment of capacity waste at the selected automotive industry. After analysing the down time data with the help of growth curves, it is concluded that there is a serious problem of capacity waste inside the selected site. Shops with maximum machine down time are shox machine shop and metal finishing shop. Implementation of later phases of Six Sigma can help scientifically in thoroughly analyzing the levels, causes and effects of a variety of factors accountable for machine down time which lead to a huge capacity waste at the selected site.

\section{Acknowledgement}

The authors would like to thank the anonymous referees for constructive comments on earlier version of this paper.

\section{References}

Alp, O., \& Tan, T. (2008). Tactical capacity management under capacity flexibility. IIE Transactions, 40(3), 221-237.

Antony, J., \& Desai, D. A. (2009). Assessing the status of Six Sigma implementation in the Indian industry: results from an exploratory empirical study. Management Research News, 32(5), 413-423.

Antony, J., Kumar, M., \& Tiwari, M. (2005). An application of Six Sigma methodology to reduce the engine-overheating problem in an automotive company. Proceedings of the Institution of Mechanical Engineers, Part B: Journal of Engineering Manufacture, 219(8), 633-646.

Bertels, T. (2003). Rath \& Strong's six sigma leadership handbook: John Wiley \& Sons.

Cheshmberah, M., \& Nabavi, S. (2014). An application of Six Sigma DMAIC methodology in outsourcing management process improvement. Uncertain Supply Chain Management, 2(3), 115-124.

Corrado, C., \& Mattey, J. (1997). Capacity utilization. The Journal of Economic Perspectives, 151167.

D'costa, A. P. (1995). The restructuring of the Indian automobile industry: Indian state and Japanese capital. World Development, 23(3), 485-502.

Dahlgaard, J. J., \& Dahlgaard-Park, S. M. (2006). Lean production, six sigma quality, TQM and company culture. The TQM magazine, 18(3), 263-281.

Esposto, F., \& Belt, M. B. (2009). Six sigma basics. USC Consulting group.

Felthoven, R. G., Horrace, W. C., \& Schnier, K. E. (2009). Estimating heterogeneous capacity and capacity utilization in a multi-species fishery. Journal of Productivity Analysis, 32(3), 173-189.

Gajanan, S., \& Malhotra, D. (2007). Measures of capacity utilization and its determinants: a study of Indian manufacturing. Applied Economics, 39(6), 765-776.

Ghosh, A., Ray, S., \& Makkar, J. (2010). Indian auto-components industry: Riding the tide. ICRA Rating Feature, December.

Goh, T. N. (2002). A strategic assessment of Six Sigma. Quality and Reliability Engineering International, 18(5), 403-410. 
Hadjleld, R., Rutherford, L., Bugge, T., \& Vigors, N. A. (2015). Automobile Industry in India.

Hahn, G. J., Hill, W. J., Hoerl, R. W., \& Zinkgraf, S. A. (1999). The impact of Six Sigma improvement - a glimpse into the future of statistics. The American Statistician, 53(3), 208-215.

Hayes, D. S. (2000). Evaluation and application of a project charter template to improve the project planning process.

Henderson, K. M., \& Evans, J. R. (2000). Successful implementation of Six Sigma: benchmarking general electric company. Benchmarking: An International Journal, 7(4), 260-282.

Hoerl, R. W., \& Snee, R. (2010). Statistical thinking and methods in quality improvement: a look to the future. Quality engineering, 22(3), 119-129.

Juran, J. M. (1954). Universals in management planning and controlling. Management Review, 43(11), $748-761$.

Karuppusami, G., \& Gandhinathan, R. (2006). Pareto analysis of critical success factors of total quality management: A literature review and analysis. The TQM magazine, 18(4), 372-385.

Krüger, J. J. (2008). Capacity utilization and technology shocks in the US manufacturing sector. International Review of Applied Economics, 22(3), 287-298.

Kumar, S., \& Arora, N. (2010). Analyzing regional variations in capacity utilization of Indian sugar industry using non-parametric frontier technique. Eurasian Journal of Business \& Economics, 2(4), $1-26$.

Li, M.-H., Al-Refaie, A., \& Yang, C.-Y. (2008). DMAIC approach to improve the capability of SMT solder printing process. Electronics Packaging Manufacturing, IEEE Transactions on, 31(2), 126133.

Linderman, K., Schroeder, R. G., \& Choo, A. S. (2006). Six Sigma: the role of goals in improvement teams. Journal of Operations Management, 24(6), 779-790.

Marsudi, M., Wahab, D., \& Haron, C. (2009). The use of spreadsheet and queuing network model to optimize capacity utilization in product development. Paper presented at the Computers \& Industrial Engineering, 2009. CIE 2009. International Conference on.

Mukherjee, A., \& Misra, R. (2012). Rbi Working Paper Series.

Orr, S. (1999). The role of capacity management in manufacturing strategy: experiences from the Australian wine industry. Technology Analysis \& Strategic Management, 11(1), 45-53.

Pyzdek, T., \& Keller, P. A. (2003). The six sigma handbook (Vol. 486): McGraw-Hill New York, NY.

Ray, S. (2013). A Close Look into Research Studies on Capacity Utilization in India and Abroad. International Journal, 2(1).

SIAM. (2013). Society of Indian Automobile Manufacturers installed capacity

Simon, K. (2007). SIPOC diagram. Retrieved January, 15, 2008.

Sonphuak, W., \& Rojanarowan, N. (2013). Strength improvement of fibre cement product. International Journal of Industrial Engineering Computations, 4(4), 505-516.

Zhang, Q., Cherkasova, L., Mi, N., \& Smirni, E. (2008). A regression-based analytic model for capacity planning of multi-tier applications. Cluster Computing, 11(3), 197-211.

$\mathrm{Zu}, \mathrm{X}$., Fredendall, L. D., \& Douglas, T. J. (2008). The evolving theory of quality management: the role of Six Sigma. Journal of operations Management, 26(5), 630-650. 